\section{Culpa da vítima: um modelo para perpetuar a impunidade nos acidentes do trabalho}

\author{
Guilty victims: a model to perpetuate \\ impunity for work-related accidents
}

Rodolfo Andrade Gouveia Vilela 1

Aparecida Mari Iguti 2

Ildeberto Muniz Almeida 3
1 Programa de Pós-graduação da Engenharia de Produção, Centro de Referência em Saúde do Trabalhador. Universidade Metodista de Piracicaba,Piracicaba, Brasil. 2 Departamento de Medicina Preventiva e Social, Universidade Estadual de Campinas, Campinas, Brasil.

3 Departamento de Saúde Pública, Faculdade

de Medicina de Botucatu, Universidade Estadual Paulista, Botucatu, Brasil.

Correspondência Rodolfo Andrade Gouveia Vilela

Programa de Pós-graduação da Engenharia de Produção, Centro de Referência em Saúde do Trabalhador Universidade Metodista de Piracicaba.

Rod. Santa Bárbara d'Oeste Iracemópolis $\mathrm{Km} \mathrm{l}$, Santa Bárbara d'Oeste, $S P$ 13450-000, Brasil.

ravilela@unimep.br

\section{Abstract}

This article analyzes reports and data from the investigation of severe and fatal work-related accidents by the Regional Institute of Criminology in Piracicaba, São Paulo State, Brazil.Some 71 accident investigation reports were analyzed from 1998, 1999, and 2000. Accidents involving machinery represented $38.0 \%$ of the total, followed by high falls (15.5\%), and electric shocks (11.3\%). The reports conclude that $80.0 \%$ of the accidents are caused by "unsafe acts" committed by workers themselves, while the lack of safety or "unsafe conditions" account for only 15.5\% of cases. Victims are blamed even in situations involving high risk in which not even minimum safety conditions are adopted, thus favoring employers' interests. Such conclusions reflect traditional reductionist explanatory models, in which accidents are viewed as simple, unicausal phenomena, generally focused on slipups and errors by the workers themselves. Despite criticism in recent decades from the technical and academic community, this concept is still hegemonic, thus jeopardizing the development of preventive policies and the improvement of work conditions.

Occupational Accidents; Occupational Safety; Working Conditions

\section{Introdução: acidentes de trabalho e sua importância}

Os acidentes do trabalho constituem fenômeno de múltiplas facetas. Sua ocorrência costuma trazer à tona no mínimo a face existencial, a técnica e a jurídica. Ou seja, simultaneamente ao drama existencial que produz para vítimas, familiares e pessoas próximas, os acidentes costumam ser seguidos de iniciativas técnicas visando a compreensão de suas causas e podem ensejar ações também na esfera judicial.

Segundo estimativas e dados da Organização Internacional do Trabalho (OIT), no plano mundial, os acidentes do trabalho causaram em 1994 um total de 335 mil mortes em acidentes típicos, que se somam a um total de $158 \mathrm{mil}$ mortes por acidentes de trabalho durante o trajeto e 325 mil mortes por doenças relacionadas ao trabalho, que totalizam 818 mil mortes no ano de 1994. Além desses dados estima-se que ocorrem anualmente 250 milhões de acidentes e 160 milhões de doenças ocupacionais 1 .

Segundo os últimos dados do Instituto Nacional de Seguridade Social (INSS), no ano de 2000 ocorreram no país 343.996 acidentes e 3.094 mortes por acidente de trabalho para uma população segurada pela Consolidação das Leis Trabalhistas (CLT) de 20.374.176, o que representa uma proporção de incidência de acidente de trabalho de 1,68 por 100 . A taxa de letalidade no ano foi de 9,0 mortes por mil aci- 
dentes e a taxa de mortalidade ficou 15,2 mortes por 100 mil trabalhadores registrados pela CLT 2. Os coeficientes de 2000 mostram que o Brasil está com taxa de mortalidade por acidentes de trabalho acima da média dos países da América Latina, que ficou em 13,5/100 mil, só perdendo para a os países da Ásia - 23.1/100 mil e da África que é de 21/100 mil, segundo o último levantamento da OIT, que tomou como base os dados do ano de 19941.

No Brasil, parte dos acidentes do trabalho que resultam em morte e lesões aos trabalhadores são objeto de investigação pelos órgãos da Secretaria de Segurança Pública (Polícia Civil). No entanto, a despeito de sua importância no que tange a iniciativas de responsabilização civil e penal, essas investigações têm sido pouco exploradas enquanto fonte de informações sobre os acidentes do trabalho graves e fatais.

As investigações do Instituto de Criminalística (IC) são efetuadas a partir de solicitação das Delegacias de Polícia que instauram inquérito policial quando ocorrem os acidentes graves e fatais do trabalho, visando a apurar responsabilidade criminal. Segundo o Manual da Secretaria de Segurança Pública do Estado de São Paulo, além da abertura do Inquérito Policial, o delegado que coordena as investigações deve registrar o Boletim de Ocorrência, com o histórico dos fatos; comparecer ao local; ouvir o trabalhador acidentado e testemunhas; inquirir e verificar junto ao empregador o cumprimento de normas de saúde e segurança no trabalho. Cabe ao delegado solicitar investigação do IC para apuração das causas do ocorrido e quando for o caso, o laudo do Instituto Médico Legal 3.

O IC, por intermédio de seu representante técnico, comparece ao local da ocorrência para investigação das causas do acidente do trabalho, emitindo laudo técnico, que irá subsidiar o delegado na apuração dos fatos e encaminhamento do inquérito. Após a fase de inquérito na Delegacia de Polícia, o caso é encaminhado para a Justiça, que, de posse das informações disponíveis dá prosseguimento aos processos. O interesse no acompanhamento e investigação dos acidentes graves e fatais foi-nos despertado a partir das experiências desenvolvidas no Programa de Saúde do Trabalhador de Piracicaba, a contar de 1998. Quatro acidentes fatais, dois do setor de papel e papelão e dois da construção civil, foram investigados pelo Programa de Saúde do Trabalhador de Piracicaba, ensejando os primeiros contatos com os laudos do IC despertando atenção para a importância da Secretaria de Segurança Pública, tanto como fonte de informações como na apuração de responsabilidades dos empregadores e seus representantes na geração de acidentes do trabalho.

Alguns casos foram objeto de inspeção de campo quando tivemos a oportunidade de confrontar os laudos com informações obtidas no local de ocorrência dos acidentes. Além de entrevistas com os acidentados, com a equipe e familiares foi possível acessar outros documentos como Atas de CIPAS, processos administrativos dos órgãos oficiais, como do Programa de Saúde do Trabalhador de Piracicaba e do Ministério do Trabalho e Emprego, além de registrar as condições de trabalho por meio de fotografias. Usando-se a aplicação do Método de Árvore de Causas (ADC) foi possível confrontar os laudos oficiais com outra abordagem, demonstrando de modo mais detalhado as distorções e simplificações resultantes da concepção monocausal conforme consta de pesquisa de Vilela 4.

\section{Concepções de acidentes}

A análise de acidentes é sempre influenciada pela visão ou compreensão do analista acerca desses eventos. No entanto, nem sempre os valores ou pontos de vista implícitos numa determinada concepção são claramente assumidos ou compreendidos por esse mesmo analista.

A própria idéia da existência de uma determinada concepção de acidente associada a cada proposta de análise pode causar estranheza tal é a freqüência com que essas propostas são enunciadas como técnicas assépticas ou neutras.

O que é o acidente? Como ele é descrito em cada uma das diferentes concepções ou "escolas de pensamento” existentes? Nos próximos parágrafos busca-se apresentar esboço de resposta a essas questões.

Inicialmente, pode-se afirmar que predomina, no Brasil e no mundo, a compreensão de que o acidente é um evento simples, com origens em uma ou poucas causas, encadeadas de modo linear e determinístico. Sua abordagem privilegia a idéia de que os acidentes decorrem de falhas dos operadores (ações ou omissões), de intervenções em que ocorre desrespeito à norma ou prescrição de segurança, enfim, "atos inseguros" originados em aspectos psicológicos dos trabalhadores. Os comportamentos são 
considerados como frutos de escolhas livres e conscientes por parte dos operadores, ensejando responsabilidade do indivíduo. A dimensão coletiva aparece associada com noção de cultura de segurança, compreendida como soma dos comportamentos dos indivíduos.

Essa abordagem associa-se a propostas de gestão da segurança e da saúde que enfatizam a vigilância e o recenseamento desses "atos inseguros ou abaixo do padrão”, a adoção de punições ou recompensas em caso de descumprimento ou de adesão às regras e a idéia da responsabilidade individual. A cultura de segurança seria construída com a adoção de estruturas hierárquicas e disciplina rígida. Em alguns casos a referência ao modelo de organizações militares e instituições totais é explícita.

Com pequenas diferenças, às vezes, apenas de ênfase segundo o autor, essa forma de conceber o acidente recebe denominações como: centrada na pessoa 5 , paradigma tradicional 6,7, paradigma burocrático da Saúde e Segurança 8 , centrada no erro 9 . Segundo Llory 6,7 , essa é a única forma de conceber o acidente que alcançou o status de paradigma, no sentido dado por Kuhn ao termo.

Infelizmente, quando se trata de apresentar outras concepções de acidentes predominam diferenças entre os autores. A seguir, de modo resumido, apresenta-se algumas das propostas de sistematização desse tema que estão presentes na literatura.

Reason 5 classifica duas concepções de acidentes como sendo "da engenharia" e a "organizacional”. A concepção da engenharia enfatiza a quantificação da probabilidade de eventos ou aspectos associados, e as falhas de concepção ensejando o surgimento de propostas de sistemas de gestão de segurança e da saúde no trabalho e de melhoria das interfaces de troca de informações. Abordagens de confiabilidade que privilegiam cálculos de probabilidade são apontadas como exemplos desse enfoque. Essa forma de conceber o acidente mostra-se pouco difundida no Brasil, sendo praticamente inexistentes experiências e publicações que a tenham adotado, sobretudo como instrumento para abordagens de acidentes.

Na concepção organizacional, Reason 5 considera que o erro é muito mais conseqüência do que causa e que suas origens estariam em condições latentes, incubadas na história do sistema.

O modelo de acidente organizacional proposto por Reason 5 enfatiza o fato do acidente apresentar origens latentes, associadas às escolhas estratégicas adotadas desde sua concepção e às políticas de gestão assumidas. $\mathrm{O}$ autor critica as análises de acidentes que res- tringem-se à identificação de falhas humanas que ocorrem nas proximidades da lesão e do acidente propriamente dito porque eles têm pouca importância para a prevenção. Segundo ele, a gestão da segurança e da saúde passa a recomendar medidas pró-ativas e a busca de reformas contínuas do sistema, como por exemplo, as estratégias de qualidade.

Apesar da referência à visão de Perrow 10 nessa proposta, a teoria do acidente normal ou sistêmico dá origem a uma concepção de acidente que tem vida própria e é adotada sobretudo em estudos de desastres ocorridos em sistemas técnicos complexos, com conseqüências que estendem-se muito além dos muros da organização em si. Na visão de Perrow, nesse tipo de sistema, sempre haverá interações de natureza inesperada, complexas, incompreensíveis em tempo real para os operadores e capazes de desencadear, de modo irreversível, o processo acidental. $\mathrm{O}$ acidente é normal não por ser freqüente, mas sim por ter origem em propriedades inerentes ao sistema.

Além da referência ao modelo de gestão do erro, acima citado, Hollnagel 9 cita dois outros: o da "gestão do desvio de desempenho" e o da "gestão da variabilidade de desempenhos".

A gestão do desvio do desempenho destaca a idéia de desvio, que teria origens em causas manifestas e latentes a serem geridas, tanto pela busca de sinais ou avisos de sua existência, quanto pela sua supressão. O termo desvio é usado para indicar mudança tanto em relação ao que é esperado e, portanto, previamente conhecido como, por exemplo, uma norma ou padrão, como em relação ao habitual, entendido de modo equivalente ao trabalho real ou atividade desenvolvida pelos operadores. $\mathrm{O}$ acidente é compreendido principalmente como sinal de disfunção no sistema sociotécnico. É enfatizada a necessidade de estender a análise além dos limites dos aspectos causais situados nas proximidades do acidente propriamente dito e de suas conseqüências. Ao citar explicitamente as causas latentes, o autor sugere que a visão apresentada por Reason também situa-se no marco dessa concepção.

A técnica de análise de acidentes dita "árvore de causas" adota como um de seus principais pilares de sustentação o conceito de variação, apresentado de modo muito próximo dessa visão, apesar da ênfase que dá ao fato de que a definição de variações deve basear-se na noção de trabalho real, e não em normas, regras ou prescrições. Aliás, é essa característica que permite sua utilização e interpretação de modo diferente deste, ou seja, como ponto de partida para demanda de análises complementa- 
res que sirvam de lastro, por exemplo, para a compreensão de comportamentos humanos aparentemente irracionais ou inusitados quando olhados sem a "perspectiva do nativo", ou seja, a compreensão daqueles que vivem o cotidiano do sistema.

A terceira concepção proposta por Hollnagel 9 dita da gestão da variabilidade de desempenhos, destaca contribuições de abordagens cognitivas rompendo com a leitura que vê o erro sempre como evento negativo. A variabilidade do trabalho tanto pode ser negativa como positiva. No caso de sistemas sócio-técnicos abertos que alcançaram bons desempenhos em termos de segurança e confiabilidade, essa variabilidade mostra-se associada, sobretudo, aos componentes humanos, sendo fortemente influenciada pela compreensão dinâmica da atividade em todos os seus momentos. Em outras palavras, trabalhar implica a adoção de estratégias cognitivas de gestão da atividade: do planejamento à execução. As representações mentais do que vai ser e do que está sendo feito são influenciadas por aspectos do tempo (hora do dia, "idade" dos componentes etc.), da história do indivíduo, dos grupos e da empresa a que se vincula, como das características técnicas e organizacionais do sistema e do contexto sócio-político-econômico em que esse está inserido. Assim é que a compreensão de um ruído, por exemplo, pode ser diferente para um novato e um trabalhador experiente; ou para um membro de equipe de empresa contratada e trabalhador da contratante que atua há anos naquele setor.

O erro é um dos sinais que orienta a compreensão da equipe acerca do que está ocorrendo, do controle ou não da atividade, em cada momento. De acordo com esse enfoque, sua ocorrência revela que a representação mental da atividade tanto dos objetivos (o que fazer), seja do como fazer, não está em consonância com a realidade. Distanciou-se dela. No entanto, os procedimentos usados para elaborar e atualizar esse modelo mental, enfim, o próprio modelo adotado, foram exatamente os mesmos usados nas situações sem acidente. De acordo com Hollnagel, 9 as origens dessa variabilidade podem ser identificadas e monitoradas.

Essa forma de pensar o trabalho leva a compreender o acidente como indicador da ruptura da compreensão da atividade, do compromisso cognitivo usado pelos operadores na gestão da atividade. No entanto, embora o acidente nos mostre o momento em que ocorre a ruptura, ele não nos permite compreender em que consiste esse compromisso. Para desvendá-lo, torna-se necessária a realização de análises complementares, entre elas, a da própria atividade.

Discutindo as abordagens do fator humano na Saúde e Segurança, Neboit 11 descreve quatro enfoques, a saber: da uni causalidade, da multicausalidade, a sistêmica e da confiabilidade humana. Segundo Neboit, o surgimento da multicausalidade representou rompimento com a visão reducionista acerca de acidentes, e serviu de base para o surgimento das compreensões sistêmicas e da confiabilidade humana que alargaram o perímetro da compreensão desses fenômenos. Segundo ele, a visão sistêmica estaria representada, sobretudo, por contribuições que romperam com a noção de Ergonomia de Posto de Trabalho introduzindo idéias como as de Confiabilidade e Ergonomia de Sistema.

Por sua vez, o enfoque da confiabilidade humana centra-se no estudo da evolução tecnológica e organizacional, explorando aspectos como os da mediação simbólica e da complexidade, e também do modo como as ciências humanas abordam o acidente.

Esses dois últimos enfoques apresentam leitura que parece associar aspectos das visões de Reason e Hollnagel, acima expostas, sem perder de vista a forma como o fenômeno acidente é abordado na Ergonomia (sobretudo na França) e por escolas das ciências humanas.

Uma perspectiva que também associa aspectos de diferentes escolas é apresentada por Llory 6,7. Seu modelo psicoorganizacional de acidentes não perde de vista a importância da compreensão de aspectos técnicos presentes em acidentes, mas ressalta sua insuficiência para a compreensão desses eventos. O acidente é apontado como potencialmente revelador de aspectos da história da organização, sobretudo daqueles relacionados às suas origens, que estavam incubados ou adormecidos. A dimensão subjetiva é reconhecida tanto em nível individual, quanto no das relações horizontais e verticais estabelecidas historicamente nas situações de trabalho. Ou seja, ressalta-se a necessidade de explorar tanto aspectos conjunturais, ditos sincrônicos, como aqueles construídos ao longo da história de vida das pessoas e da organização, ditos diacrônicos.

No Brasil, o modelo explicativo monocausal centrado na culpa da vítima vem se mantendo intocável no meio técnico - industrial, em meios acadêmicos mais conservadores e em organismos oficiais como mostraremos neste estudo, mesmo após inúmeras críticas publicadas nas décadas de 80 e 90 12,13,14,15.

Esta manutenção silenciosa não seria uma demonstração de que este modelo é convenien- 
te e interessante para esconder as verdadeiras causas dos acidentes do trabalho?

Recente campanha da Confederação Nacional da Industria (CNI) repete em folhetos e cartazes o conteúdo das mensagens dos cartazes das décadas de 70 e 80 . Um deles mostra uma mão embaixo de um martelo de uma prensa mecânica sem proteção na zona de risco (portanto uma máquina desprotegida, com zona de prensagem aberta, caracterizando situação de risco grave e iminente - que deveria ser proibida de operar) com dizeres: "Atenção ao trabalhar com prensas!" 16,17,18.

Nesse estudo explora-se o conteúdo de análises de acidentes do trabalho graves, conduzidas por organismo técnico policial. A questão central do estudo refere-se à identificação de concepções de acidentes adotadas e de implicações associadas às conclusões dessas investigações. Antes disso, apresenta-se breve relato de estudos que exploraram o mesmo tema com base em análises conduzidas no âmbito de empresas, publicações, material de divulgação dito de prevenção de acidentes e discurso de vítimas de acidentes atendidas em instituição pública.

\section{Fonte de informações e método}

Em contato formal com o IC de Piracicaba, obtivemos acesso a 104 laudos produzidos para investigação de causas de acidentes ocorridos entre (data) e (data) na cidade de Piracicaba e em alguns municípios vizinhos. O material foi fornecido na forma de gravação eletrônica (CD), cujos textos não vieram acompanhados de informações complementares como fotografias, cópias dos Boletins de Ocorrência e outros documentos como cópia das CATs etc. Dos laudos fornecidos foram selecionados 71 casos de acidentes graves e fatais do trabalho para estudo, pois os demais não eram relacionados ao trabalho ou estavam incompletos, impossibilitando o estudo.

Os casos selecionados foram distribuídos segundo a localidade onde ocorreu a lesão e causas, conforme conclusões emitidas nos laudos. Eles foram classificados quanto à categoria da atividade econômica do empreendimento em que ocorreu o acidente, causa externa da lesão segundo a Classificação Internacional de Doenças - 10a versão (CID-10) 19 e segundo tipologia proposta por Monteau 20, sendo distribuídos em grupos 1 e 2. Nesta divisão, os acidentes pertencentes ao Grupo 1 ocorrem em situações de risco evidente, cujos fatores de risco estão presentes de modo habitual no processo de trabalho e que podem ser facilmente identi-

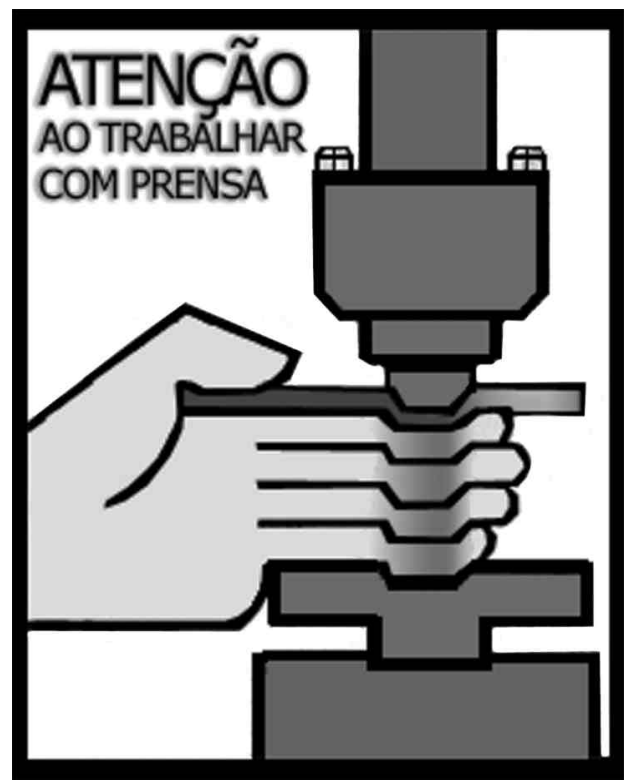

Detalhe: cartaz mostra a mão do trabalhador sendo prensada ao ingressar na zona de operação do equipamento. A máquina desprotegida permite o acesso da mão na zona de risco, em desacordo com as normas atuais de proteção (Norma Regulamentadora no 12 do Ministério do Trabalho e Emprego, e Norma Brasileira da ABNT). O cartaz induz a uma culpabilização transferindo a responsabilidade para o operador. A máquina sem proteção pode ser operada desde que o operador preste atenção, tome cuidado.

ficados por meio de simples inspeção. Já os acidentes do Grupo 2 necessitam de conjunção de fatores que não ocorrem de modo habitual e de técnicas mais apuradas para investigação de causas, como entrevistas aos operadores, observação das atividades de trabalho etc.

O modelo de laudo, as descrições dos acidentes e as conclusões relativas a causas do evento foram comparados com as concepções de acidentes apresentadas, de modo a possibilitar identificação da concepção presente no modelo de investigação adotado na Instituição. Alguns casos selecionados são apresentados e discutidos.

\section{Resultados}

A maioria dos laudos referiam-se a acidentes ocorridos na cidade de Piracicaba, que responde por $41,0 \%$ dos eventos, seguida das cidades 
de Araras (17,0\%), Limeira (12,7\%), Americana $(5,6 \%)$ e Rio das Pedras $(4,2 \%)$. As demais $11 \mathrm{ci}-$ dades da região totalizaram 14 casos do conjunto. Tal situação pode ser explicada pelo maior contingente de trabalhadores e maior densidade econômica das cidades pólo comparadas com as vizinhas.

A distribuição dos casos de acordo com a atividade econômica do empreendimento em que ocorreu o acidente, mostra que os ramos de atividade que apresentam maior freqüência de casos são os da indústria de produtos alimentícios e de bebidas, com 16,9\% dos casos, seguido do setor da construção civil, com 15,5\%. Em seguida, surge o setor de fabricação de papel e celulose, que responde por $11,2 \%$ do universo estudado. Destaca-se ainda o fato de que o setor da indústria de transformação responde por 41 casos, o que equivale a $58,0 \%$ das ocorrências, enquanto que outros grupos de atividade econômica, como o setor primário (agrícola e extrativo), respondem por $11,2 \%$ e o setor de comércio e serviços por $15,5 \%$ dos casos.

As causas externas das lesões foram agrupadas segundo a CID-10 19. Podemos observar que as máquinas, exceto as agrícolas, respondem por $38,0 \%$ das ocorrências em estudo. A queda de altura responde por $15,5 \%$ das ocorrências e os acidentes causados por corrente elétrica respondem por $11,3 \%$ dos casos. Em seguida, surgem os acidentes causados por equipamento agrícola incluindo tratores com $8,5 \%$ dos casos.

A Tabela 1 mostra a distribuição das conclusões das análises em termos de "causa apurada”. Dos 71 casos investigados, quarenta, ou seja $56,3 \%$, foram atribuídos a atos inseguros cometidos pelos trabalhadores. Por sua vez, 17 casos $(24,0 \%)$ foram atribuídos a atos inseguros cometidos pelos trabalhadores e seus mentores. A falta de segurança ou condição insegura de trabalho responde por 11 casos, representando $15,5 \%$. Observa-se que a menção aos atos inseguros seja do trabalhador acidentado e/ou dos mentores, responde por um total de $80,3 \%$ do universo.

A presença de campo denominado "causa apurada" no modelo de laudo adotado nas investigações não parece ser fruto de acaso. A mesma expressão, no singular, foi adotada durante anos em modelo de análise de acidente recomendado em norma regulamentadora do Ministério do Trabalho e Emprego e em norma brasileira referente à investigação de acidentes do trabalho. Sua presença em laudos do IC sugere que o modelo adotado tenha encontrado inspiração nessas fontes. As conclusões redigidas com uso das noções de atos e condições inseguras, ou seja, as mesmas adotadas durante anos no campo da Saúde e Segurança do Trabalho, reforçam essa idéia.

Por si só, esses elementos já permitem afirmar que a concepção de acidente subjacente a essas análises é a mesma anteriormente descrita como "centrada na pessoa", gestão do erro, paradigma tradicional ou burocrático da saúde e segurança no trabalho. O uso do singular na denominação do campo "causa apurada" revela a natureza simplista com que se vê o acidente. Descrições sucintas, restringindo-se quase que exclusivamente à desestabilização do sistema e às origens da lesão confirmam essa afirmação.

Discutindo implicações de análises que atribuem o acidente a comportamentos dos operadores, Lima \& Assunção 21 (p. 95), afirmam: "não é a conclusão quanto aos atos inseguros que leva à prevenção baseada em mudanças de atitude e de comportamento, mas sim a concepção racionalista de que o comportamento humano é determinado exclusivamente pela consciência e que, portanto, o acidente decorre da falta de consciência do risco".

Outro autor que também destaca a inadequação da concepção de ser humano presente nas práticas tradicionais de segurança é Llory 6 (p. 150). Referindo-se a seus colegas engenheiros, ele afirma: "os engenheiros esquecem o medo, a incerteza, o sofrimento, a incapacidade de manter a atenção a todos os instantes, os perigos da agressividade, às vezes, da violência, eles desconhecem as frustrações, o mal-estar, a desmobilização subjetiva". "Eles concebem o homem com um ser sem corpo ou sem moral respondendo essencialmente aos imperativos das sanções $e$ ou aos atrativos de uma recompensa...".

Essa incapacidade de compreender e incorporar a concepção de homem, contemporânea da evolução dos conhecimentos, aparece como

Tabela 1

Freqüência, porcentagem e porcentagem acumulada de acidentes de trabalho típicos graves e fatais, analisados pelo Instituto de Criminalística de Piracicaba segundo a conclusão - causa apurada.

\begin{tabular}{lccc}
\hline Classificação & Quantidade & $\%$ & $\%$ acumulada \\
\hline Ato inseguro & 40 & 56,3 & 56,6 \\
Ato inseguro do trabalhador & 17 & 24,0 & 80,3 \\
e/ou dos mentores & 11 & 15,5 & 95,8 \\
Falta de segurança & 3 & 4,2 & 100,0 \\
Outros não conclusos & 71 & 100,0 & - \\
Total & & & \\
\hline
\end{tabular}


um dos maiores problemas de análises de acidentes baseadas na concepção tradicional de Saúde e Segurança. Uma das conseqüências mais perversas associadas a essas análises é a adoção de leituras acerca dos comportamentos humanos presentes nos acidentes que sistematicamente desconsideram o contexto ou situação em que ocorrem. Entre os aspectos não abordados nessas análises pode-se citar: (a) atividade que estava sendo desenvolvida, aí incluída as noções de prescrições, objetivos, recursos disponibilizados, os aspectos temporais, sua variabilidade normal e incidental etc.; (b) influências do contexto externo ao sistema, como urgência de pedidos de fornecedores, exigências de legislação etc.; (c) variações do estado psíquico dos trabalhadores, inclusive aquelas referentes a aspectos da gestão da atividade, como a ansiedade decorrente de dificuldades na resolução de problemas etc.

Estudando a tipologia dos acidentes quanto à sua complexidade e possibilidade de identificação das causas durante investigação, conforme proposto por Binder \& Almeida, 22 utilizamos a descrição encontrada nos laudos e observamos que dos 71 casos 37 podem ser enquadrados como pertencentes a acidentes do Grupo 1, representando 52,0\% do total, enquanto que 18 casos podem ser enquadrados como do Grupo 2, representando 25,5\%, e 16 casos não permitem uma classificação precisa por falta de informações complementares.

Esses achados reforçam a necessidade de ações de vigilância e de promoção à saúde dos trabalhadores nos segmentos produtivos, com atenção aos fatores causais de maior relevância como máquinas e equipamentos, queda de altura e acidentes com eletricidade.

A presença de tais fatores causais revela que no contexto local e regional os problemas clássicos de segurança do trabalho não estão equacionados, persistindo processos e condições de elevado risco, com a maioria dos casos (52,0\%) classificados como do Grupo 1 de Monteau, ou seja, acidentes com relativa facilidade para identificação de suas causas, por meio de inspeções simples, em situações onde é flagrante e visível o desrespeito às regras mínimas de segurança.

\section{Discussão: atribuindo culpa e abrindo caminho para a impunidade}

Os casos apresentados a seguir podem ser considerados como emblemáticos de investigações que adotam a concepção tradicional de saúde e segurança.
Acidente: trabalhador é ferido na região do pescoço com a ponta da lâmina de uma roçadeira de mato tipo costal motorizada. A lâmina rompeu-se ao atingir uma pedra conforme atesta o exame pericial.

“Conclusão: do observado e do relatado, a causa do acidente deu-se em função de uma somatória de atos inconseqüentes, a saber:

- utilização inadequada do equipamento, uma vez que o local não é propício, dada a existência de pedras de cobertura;

- operar o equipamento sem a proteção devida da ferramenta de corte;

- não utilizar o cinto de apoio recomendado;

- utilizar a ferramenta não recomendada pelo fabricante (faca dupla metálica).

Do exposto conclui-se que o acidente ocorreu em função de atos inseguros caracterizados por negligência e imprudência, potencializados pela inobservância por parte dos mentores e fiscalizadores no cumprimento das normas regulamentadoras e no obedecimento das instruções de operação e manuseio ditadas pelo fabricante. Era o que havia a relatar" (Fonte: Superintendência da Polícia Técnica e Científica 23).

Esta é a reprodução de conclusão de um dos laudos que foram objeto desta pesquisa, numa situação característica em que se imputa culpa ao acidentado por decisões que não estão ao seu alcance. Como é feito habitualmente esse tipo de trabalho na empresa? Que aspectos organizacionais e individuais modelam ou determinam a forma de fazê-lo? Quem "escolhe” o local em que ele será executado? Por acaso existe terreno isento de pedras? Quem decide o tipo de ferramenta a ser usada na execução da tarefa? E por acaso existe lâmina de aço disponível no mercado que seja inquebrável, resistente a impactos desta natureza? O ambiente de produção, especialmente no Brasil, é um terreno definido, de antemão imposto por relações hierárquicas rígidas e relações de trabalho essencialmente autoritárias.

Chama a atenção o fato de que em grande número de casos, mesmo reconhecendo a existência de várias situações de risco evidentes no local de trabalho, a conclusão é enfática em atribuir culpa às vítimas: "certificou-se que a referida obra não obedecia os critérios mínimos exigidos pelas Normas Regulamentadoras de Segurança e Medicina do Trabalho ... especificamente no tocante a trabalhos em alturas, sendo observado: - ausência de tapumes frontais para isolamento de transeuntes... - área de trabalho conturbada e impedida - emprego de poucas e estreitas pranchas de tábuas nos andaimes - presença de entrelaçamento de tábuas nos andaimes sem critério técnico de sustenta- 
ção - apoios instáveis de andaimes, tanto na vertical e horizontal - piso acidentado". O laudo conclui que o acidente "deu-se em função dum ato inseguro por parte da vítima, caracterizado por negligência e imprudência, potencializado pela inexistência de critérios técnicos de segurança presentes na obra, e acima descrito" (Fonte: Superintendência da Polícia Técnica e Científica 23).

Em outro caso, dois trabalhadores desmaiam ao acessar área contendo gases de uma galeria de esgotos, sem que fossem tomadas as medidas mínimas de segurança como ventilação forçada ou fornecimento de proteção individual, com suprimento de ar externo, falta de monitoramento do ambiente etc., a conclusão é taxativa alegando que o acidente é causado por: “ato inseguro caracterizado por imprudência e negligência por parte da vítima e seus mentores, pela inexistência de política preventiva a acidentes do trabalho, sinalização de alertas e cuidados, normas,procedimentos e treinamentos alusivos a este tipo de atividade" (Fonte: Superintendência da Polícia Técnica e Científica 23).

\section{Considerações finais - os laudos e suas conclusões}

Os laudos fornecidos para análise na forma de CD representaram limites para estudo mais aprofundado, uma vez que não permitiam acesso a outras informações que pudessem elucidar questões como o resultado das lesões, acidentes levaram a óbito, existência ou não de vínculo formal de emprego dos trabalhadores acidentados etc. Mesmo com estas limitações, o estudo revela que as máquinas estão envolvidas na gênese da maioria dos acidentes graves e fatais na região, seguidos dos acidentes causados por queda de altura e choques elétricos, o que confirma estudos recentes sobre causa de acidentes graves e fatais 24 .

Apesar das limitações das informações apresentadas para estudo, o acesso aos dados obtidos pela Secretaria de Segurança Pública, constitui uma importante fonte de informações, que podem ser úteis para investigação e vigilância em saúde do trabalhador, especialmente para os acidentes graves e fatais.

Em todos os casos a conclusão apresentada mostra-se circunscrita a acontecimentos situados nas proximidades da lesão e do acidente propriamente dito. Pior ainda, atribuindo a esses fatos papel determinante na avaliação do processo causal.

Em todos eles verifica-se a repetição de referências a comportamentos "inadequados", “não recomendados”, omissões ou similares definidos com base em padrão fruto de idealização do analista acerca de qual "deveria ser" o comportamento seguro naquela situação. A adesão da vítima a esse padrão é tomada como obrigatória e inalterável em todas as situações e contextos, como se a mera suposição de sua existência representasse condição necessária e suficiente para a adesão dos trabalhadores. Ou seja, independentemente de mudanças no desenvolvimento da atividade e no estado fisiológico e psicológico dos indivíduos que a realizam.

Esses achados mostram que as análises adotam a perspectiva tradicional apontada em diversos momentos nesse artigo, que entende os acidentes como fenômenos simples e unicausais, resultando em conclusões que descarregam nos trabalhadores as responsabilidades pelos acidentes do trabalho. Estas conclusões serão utilizadas em eventuais processos de responsabilidade civil e penal com favorecimento dos interesses dos empregadores.

Merece destaque o uso da idéia de ato inseguro para configuração sistemática da culpa da vítima nos casos de acidentes do trabalho. Construiu-se então um modelo conveniente e útil para a descaracterização da culpa do empregador ou de seus prepostos, mantendo-se deste modo um clima de impunidade em relação aos acidentes do trabalho. Cabe destaque o fato de que nossa teoria jurídica no acidente de trabalho assenta-se na responsabilidade subjetiva, baseada na necessidade de demonstração de culpa do empregador para dar fundamento aos processos civil e criminal. Segundo os Códigos Civil e Penal Brasileiros, não cabe reparação civil ou processo penal quando o acidente tiver ocorrido "por culpa exclusiva da vítima" ou nas hipóteses de caso fortuito ou de força maior 25 .

Do ponto de vista da prevenção, as conclusões emitidas reforçam a idéia e a cultura em vigor de que as medidas cabíveis para se evitar novas ocorrências devem ser centradas na mudança do comportamento dos trabalhadores, para que estes prestem mais atenção, tomem cuidado etc., permanecendo intocadas as condições, processos de trabalho, atividades e meios produtivos que são assim naturalizados - assumidos como perigosos.

Embora este estudo não tenha explorado as razões da escolha desse modelo de análise por parte do IC de Piracicaba, seus achados apontam para a necessidade de se investir na capacitação e reciclagem dos profissionais desse instituto no tocante às concepções e métodos de investigação de acidentes do trabalho, bem 
como na aproximação e tentativa de articulação de ações conjuntas com as Secretarias de Segurança Pública e os órgãos responsáveis pela vigilância em Saúde do Trabalhador.

A pequena revisão apresentada na introdução deste texto sobre concepções de acidentes, pode ser tomada como sugestão de conteúdos que precisariam ser abordados em proposta de formação de técnicos responsáveis pela condução desse tipo de investigações.

\section{Resumo}

Neste artigo analisam-se os laudos e dados obtidos das investigações de acidentes graves e fatais do trabalho efetuadas pelo Instituto de Criminalística (IC), Regional de Piracicaba. Foram analisados 71 laudos de acidentes ocorridos em 1998, 1999 e 2000. Os acidentes envolvendo máquinas representam 38,0\%, seguido pelas quedas de altura $(15,5 \%)$ e em terceiro lugar os causados por corrente elétrica (11,3\%). Os laudos concluem que $80,0 \%$ dos acidentes são causados por "atos inseguros" cometidos pelos trabalhadores, enquanto que a falta de segurança ou "condição insegura" responde por 15,5\% dos casos. A responsabilização das vítimas ocorre mesmo em situações de elevado risco em que não são adotadas as mínimas condições de segurança, com repercussão favorável ao interesse dos empregadores. Observa-se que estas conclusões refletem os modelos explicativos tradicionais, reducionistas, em que os acidentes são fenômenos simples, de causa única,centrada via de regra nos erros e falhas das próprias vítimas. A despeito das críticas que tem recebido nas duas últimas décadas no meio técnico e acadêmico, esta concepção mantém-se hegemônica prejudicando o desenvolvimento de políticas preventivas e a melhoria das condições de trabalho.

Acidentes de Trabalho; Segurança do Trabalho;Condições de Trabalho

\section{Colaboradores}

R. A. G. Vilela elaborou e redigiu o corpo do artigo. A. M. Iguti participou da revisão da primeira versão do artigo; I. M. Almeida contribuiu em releituras, mudanças na discussão inicial e acréscimos na versão final do manuscrito.
Outras pesquisas necessitam ser efetuadas para entender a contribuição das investigações de causas e suas repercussões na apuração de responsabilidades junto aos inquéritos promovidos pela Secretaria de Segurança Pública, bem como as repercussões destes inquéritos nas políticas de saúde e segurança adotadas pelas empresas.

\section{Referências}

1. Takala J. Global estimates of fatal occupational accidents. Special Supplement, Sixteenth International Conference of Labour Statisticians, International Labour Organization. http//www.oit. org (acessado em 15/Mai/1998).

2. Instituto Nacional de Seguridade Social. Dados estatísticos de acidentes do trabalho da previdência social. http//www.mpas.gov.br (acessado em 15/Out/2002).

3. Secretaria de Segurança Pública de São Paulo. Polícia e acidentes do Trabalho. São Paulo: Fundação Jorge Duprat Figueiredo de Segurança e Medicina do Trabalho/Delegacia Regional do Trabalho; 1998.

4. Vilela RAG. Desafios da vigilância e da prevenção de acidentes do trabalho: a experiência do programa de saúde do trabalhador de Piracicaba; construindo prevenção e desvelando a impunidade [Tese de Doutorado]. Campinas: Faculdade de Ciências Médicas, Universidade Estadual de Campinas; 2002.

5. Reason J. Reconciling the different approaches to safety management In: Reason J, editor. Managing the risks of organizational accidents. Aldershot: Ashgate Publishing; 1997. p. 223-41.

6. Llory M. Acidentes industriais: o custo do silêncio. Rio de Janeiro: Editora MultiMais; 1999.

7. Llory M. Postface. In: Llory M, editor. L'accident de la centrale nucléaire de Three Mile Island'. Paris: L'Harmattan; 1999. p. 337-42.

8. Dwyer T. A study on safety and health management at work a multidimensional view from a developing country. In: Frick K, Jensen PL, Quinlan $M$, Wilthagen T, editors. Systematic occupational health and safety management. Amsterdam: Pergamon/National Institute for Working Life; 2000. p. 149-74. 
9. Hollnagel E. Accident models and accident analysis. http:// www.ida.liu.se/ eriho (acessado em 15/Set/2003).

10. Perrow C. Normal accident. Living with high risk technologies. Princeton: Princeton University Press; 1999.

11. Neboit M. Abordagem dos fatores humanos na prevenção de riscos do trabalho. http:/ / www.trabalho.gov.br (acessado em 15/Set/2003).

12. Cohn A, Karsch US, Hirano S, Sato AK. Acidentes de trabalho: uma forma de violência. São Paulo: CEDEC/Brasiliense; 1985.

13. Carmo JC, Almeida IM, Binder MCP, Settini MM. Acidente do trabalho. In: Mendes R, organizador. Patologia do trabalho. Belo Horizonte: Editora Ateneu; 1995. p. 431-55.

14. Binder MC, Almeida IM, Azevedo ND. A construção da culpa. Trabalho e Saúde 1994; 14:15-7.

15. Machado JMH, Minayo-Gomez C. Acidentes de trabalho: concepções e dados. In: Minayo MC, organizador. Os muitos Brasis. São Paulo: Editora Hucitec; 1995. p. 117-42.

16. Confederação Nacional da Indústria/Serviço Social da Indústria/Serviço Nacional de Aprendizagem Industrial. Prevenção é vida. Campanha da indústria para prevenção de acidentes do trabalho. História em quadrinhos. São Paulo: Confederação Nacional da Indústria/Serviço Social da Indústria/Serviço Nacional de Aprendizagem Industrial; 2000.

17. Serviço Social da Indústria. Cartazes de segurança. Modelos de cartazes sobre segurança no trabalho. São Paulo: Serviço Social da Indústria; 2000.
18. Confederação Nacional da Indústria. Prevenção é vida. Campanha da Indústria para Prevenção de Acidentes do Trabalho - 1999. São Paulo: Confederação Nacional da Indústria; 1999. (mimeo.)

19. Organização Mundial da Saúde. Classificação Estatística Internacional de Doenças e Problemas Relacionados à Saúde, 10a Revisão. v. 1. São Paulo: Centro Colaborador da OMS para a Classificação de Doenças em Português; 1995.

20. Monteau M. Accident analyses. In: Encyclopedia of occupational health and safety. $3^{\text {rd }}$ Ed. Geneva: International Labour Office; 1989. p. 13-6.

21. Lima FPA, Assunção AA. Para uma nova abordagem da segurança do trabalho. In: Lima FPA, Assunção AA, organizadores. Análise dos acidentes: Cia. de Aços Especiais Itabira. Belo Horizonte: Laboratório de Ergonomia, Universidade Federal de Minas Gerais; 2000. p. 83-115.

22. Binder MCP, Almeida IM. Investigação de acidentes do trabalho. Botucatu: Universidade Estadual Paulista; 2000. (mimeo.)

23. Superintendência da Polícia Técnica e Científica, Instituto de Criminalística. Laudos de acidentes do trabalho investigados nos anos de 1997-2000 [CD-ROM]. Piracicaba: Superintendência da Polícia Técnica e Científica, Instituto de Criminalística; 2000 .

24. Gawryszewski M, Mantovanini JA, Liung LP. Acidentes do trabalho fatais. Estudo sobre acidentes de trabalho fatais no Estado de São Paulo no ano de 1995. São Paulo: Ministério do Trabalho e Emprego; 1998. (mimeo.)

25. Oliveira SG. Proteção jurídica à saúde do trabalhador. 2a Ed. São Paulo: Editora LTR; 1998.

Recebido em 12/Mar/2003

Versão final reapresentada em 29/Set/2003

Aprovado em 23/Out/2003 